\title{
Pesquisar o Ensino de Ciências é entrelaçar fronteiras
}

\section{Editorial}

A Red Internacional de Investigación en Enseñanza de las Ciencias (RIEC), surgiu em 2017 e vem se expandindo desde então pelo esforço de pesquisadores de Programas de Pós-Graduação que fazem pesquisa na área de Ensino de Ciências e que participam por meio de suas Instituições.

Atualmente a RIEC tem sede na Universidade Pedagógica Nacional (UPN), em Bogotá$\mathrm{CO}$, atua com escopo pautado por: "espaço de interação, formação de pesquisadores e produção de pesquisas de Pós-graduação que tenham interesse em temas ligados ao Ensino de Ciências" e tem como área de atuação principal a Investigação em Ensino das: Ciências da Natureza (Biologia, Física e Química), Ensino de Ciências, Educação Ambiental, Matemática, Engenharias e Tecnologias.

Com o objetivo geral de "favorecer a inter-relação entre diferentes instituições e Programas de Pós-graduação e a fim de ampliar as estratégias de pesquisa, inovação, socialização, e desenvolvimento da Pós-graduação em nível internacional”, está formada atualmente por mais de 20 instituições, de diferentes grupos de pesquisa e Programas de Pós-graduação de quatro países diferentes, a saber: Argentina, Brasil, Chile e Colômbia.

Um dos objetivos específicos da RIEC é desenvolver atividades de cooperação em nível de Pós-Graduação e aprofundar compreensões sobre a Pesquisa em Ensino de Ciências, e, neste sentido, temos desenvolvido pesquisas conjuntas e aberto espaços e tempos de produção coletiva. No cenário atual, também, percebemos que não se faz pesquisa em nível de Pós-Graduação sem o processo de internacionalização, que se inicia pela constituição de redes de pesquisa que ampliem estes espaços e tempos formativos para além das fronteiras de cada País e de cada Programa de Pós-Graduação. Neste contexto, uma das formas de estreitarmos laços, aproximarmos as distâncias, projetarmos a RIEC e visualizarmos seus membros, temáticas de pesquisa e suas formas de pesquisar o ensino de Ciências na Pós-Graduação é abrir espaços de divulgação das pesquisas de seus membros nos diferentes periódicos das instituições que participam da Rede.

Assim, a Revista Insignare Scientia (RIS) da Universidade Federal da Fronteira Sul (UFFS) abriu uma chamada para pesquisadores membros da RIEC sobre a Pesquisa no 
Ensino de Ciências em nível de Pós-Graduação. Como um primeiro movimento de interrelação entre os pares e com objetivo de tornar as produções disponíveis nos diferentes países e línguas que compõe a RIEC apresentamos esta Edição Especial: Pesquisa na PósGraduação em Ensino de Ciências, Volume 4, Número 5, 2021 da RIS. A chamada foi coordenada pelas pesquisadoras: Dra. Cleci Werner da Rosa - Universidade de Passo Fundo (UPF), Brasil, Dra. Diana Lineth Parga Lozano - UPN, Colômbia e Dra. Fabiane de Andrade Leite - UFFS, Brasil, todas pesquisadoras da RIEC.

O volume especial da RIS apresenta 18 artigos com pesquisadores dos quatro países da RIEC que escreveram sobre temáticas relevantes à área de Ensino de Ciências, tomadas como enfoque/eixo de investigação e se apresentaram todas atravessando processos de Ensino, sendo frutos de esforços de pesquisa. São elas: meio ambiente, germinação, biomas brasileiros, tecnologias, objetos de aprendizagem, situação-problema, pandemia, negacionismo científico, pesquisa educacional, saberes docentes, formação de professores, praxeologia, formação profissional, Pós-Graduação, ensino de Ciências, políticas públicas educacionais, avaliações externas, pensamento crítico, habilidades investigativas, ambientalização curricular, desenvolvimento curricular, iniciação científica, alfabetização científica, ensino de química, educação ambiental, educação em saúde, educação STEM, ensino de Ciências Exatas, experimentação.

É possível perceber com a leitura que as matizes teóricas são diversas o que implica reconhecer que são inúmeras possibilidades de perceber a pesquisa de Pós-Graduação da área de Ensino de Ciências e afins, o que nos coloca sempre no desafio de nos movimentarmos do que sabemos ao que podemos aprender e do como pesquisamos até o que os outros pesquisam. Este duplo movimento amplia as inter-relações de pesquisa e de ensino e viabiliza o diálogo entre pares, entre Programas, Países e línguas com distintas interfaces e objetivo em comum: melhorar os processos de ensinar e de aprender Ciências. Assim acreditando que na atualidade pesquisar e ensinar Ciências é entrelaçar fronteiras, convido a todos a leitura dos artigos.

Prof. Dr. Roque Ismael da Costa Güllich - UFFS Coordenação Geral da RIEC 